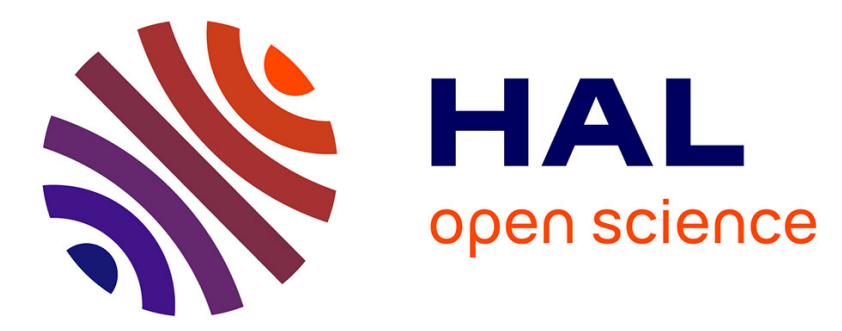

\title{
Consolidation of artificially degraded polyurethane ester foam with aminoalkylalkoxysilanes
}

\author{
Eleonora Pellizzi, Agnès Lattuati-Derieux, Jean-Baptiste D'espinose de \\ Lacaillerie, Bertrand Lavédrine, Hervé Cheradame
}

\section{To cite this version:}

Eleonora Pellizzi, Agnès Lattuati-Derieux, Jean-Baptiste D'espinose de Lacaillerie, Bertrand Lavédrine, Hervé Cheradame. Consolidation of artificially degraded polyurethane ester foam with aminoalkylalkoxysilanes. Polymer Degradation and Stability, 2016, 129, pp.106-113. 10.1016/j.polymdegradstab.2016.04.007 . hal-01311334

\section{HAL Id: hal-01311334 https: / hal.sorbonne-universite.fr/hal-01311334}

Submitted on 4 May 2016

HAL is a multi-disciplinary open access archive for the deposit and dissemination of scientific research documents, whether they are published or not. The documents may come from teaching and research institutions in France or abroad, or from public or private research centers.
L'archive ouverte pluridisciplinaire HAL, est destinée au dépôt et à la diffusion de documents scientifiques de niveau recherche, publiés ou non, émanant des établissements d'enseignement et de recherche français ou étrangers, des laboratoires publics ou privés. 


\section{Consolidation of Artificially Degraded Polyurethane Ester Foam with Aminoalkylalkoxysilanes}

Eleonora Pellizzi ${ }^{a}, \mathrm{~b}, \mathrm{c}, *$, Agnès Lattuati-Derieux ${ }^{\mathrm{a}}$, Jean-Baptiste d'Espinose de Lacaillerie $^{b}$, Bertrand Lavédrine ${ }^{\mathrm{a}}$, Hervé Cheradame ${ }^{\mathrm{c}}$

${ }^{a}$ Centre de Recherche sur la Conservation des Collections (CRC, USR 3224), Sorbonne Universités, Muséum National d'Histoire Naturelle, Ministere de la Culture et de la Communication, CNRS, CP 2136 rue Geoffroy St Hilaire, 75005 Paris, France

${ }^{b}$ Sciences et Ingénierie de la Matière Molle - PSL University - ESPCI ParisTech, UMR UPMC CNRS 7615, 10 rue Vauquelin, 75005 Paris, France

${ }^{c}$ Laboratoire Analyse et Modélisation pour la Biologie et l'Environnement - Université d'Évry Val d'Essonne, UMR CNRS 8587, Boulevard François Mitterrand, 91025 Évry, France

\section{Abstract}

Museum artifacts made of polyurethane ester foam are frequently affected by conservation issues mainly related to the loss of their mechanical properties. Modification of mechanical properties often leads to structure crumbling and in some cases to the loss of the entire artifact. A previous study evaluated the possibility to reinforce new flexible industrial polyurethane ester foam with aminoalkylalkoxysilane (AAAS) based treatments. In this paper AAAS are applied on artificially degraded polyurethane ester foam to investigate the possibility to reinforce already degraded objects. Two AAAS, the 3-Aminopropylmethyldiethoxysilane and the N-(2-Aminoethyl)-3-aminopropylmethyldimethoxysilane have been tested. AAAS solutions at different concentrations have been used to apply the monomers on the foam samples by

\footnotetext{
*corresponding author

Email address: pellizzi@mnhn.fr (Eleonora Pellizzi)
} 
immersion. Mechanical properties have been studied by Compression Force Deflection Test, which shows that after AAAS treatment the resistance of the foam to compression improves and the cell collapse is prevented. The color of the samples, before and after consolidation, has been monitored to assess the impact of the treatment on the visual aspect of the foam. AAAS distribution in the thickness of the samples has been investigated by Fourier Transform Infrared Spectroscopy (FTIR) and Scanning Electron Microscopy (SEM). Silicon Magic angle spinning nuclear magnetic resonance $\left({ }^{29} \mathrm{Si}\right.$ MAS NMR) has been used to confirm AAAS polymerization and to evaluate its average polymer chain length. ${ }^{29} \mathrm{Si}$ MAS NMR has also been used to investigate the behavior of AAAS polymers in time by analyzing four years old reinforced samples. The results highlighted the stability of the poly-AAAS chains after four years of natural aging.

Keywords: Aminoalkylalkoxysilanes, Polyurethane, Foams, Reinforcement, Artificial degradation, Contemporary art, Conservation

\section{Introduction}

Because of their multiple applications, since the 1960s, polyurethanes (PURs) attract artists and designers, who use them for sculptures, paintings, design furniture, textiles and accessories [1] [2]. Among several kind of PURs, PUR foam made from polyester polyols are particularly difficult to conserve because of their high sensitivity to environmental moisture [3] [4] [5]. Hydrolysis of PUR ester chains is at the origin of the mechanical properties loss of the structure and leads to foam crumbling [6].

For PUR ester foams the effects of hydrolytic degradation can rapidly 
appear after 20-30 years of natural aging. Several studies concerning degradation and conservation strategies for PUR foams used by artists are reported in the literature [7] [8] [9] [10] [11]. Open cell polyurethane foams are especially sensitive to degradation because the many open pores give them a large internal surface and exchanges with the external environment are promoted [12]. For close cell foams exchanges with the gases from the atmosphere are limited; humidity, oxygen and pollutants hardly diffuse into the foam structure. Close cell PUR ester foams are then less sensitive to hydrolysis (and in general to degradation) than open cell foams. For this reason the present study focus only on open cell flexible foams because they are more prone to degradation.

While van Oosten [13] reported that impregnation of flexible PUR ether foam with a mixture of Impranil DLV and vitamin E (an anti-oxidant) inhibits the photo-oxidation and gives flexibility to PUR ether foam, no convenient consolidation treatment exists for PUR ester foams at the moment. For this reason several international institutions worked on new protocols to analyze and conserve plastic artworks and some of them focused their research on conservation treatments for PUR foams objects [14]. This research was part of the POPART program and the present paper presents the major results of one of the studies.

Two aminoalkylalcoxysilanes (AAAS), the 3-aminopropylmethyldiethoxysilane (AMDES) and the N-(2-Aminoethyl)-3-aminopropylmethyldimethoxysilane (DIAMINO) have already been tested on modern industrial flexible open cell PUR ester foam samples to evaluate the possibility to employ these products for preventive conservation treatment [15]. This first study demon- 
strated that after treatment a reinforcement effect is obtained. AAAS polymerize on the cell surfaces and partially penetrate into the cell edge thickness. Therefore the reinforcement effect is probably the consequence of the formation of an interpenetrating polymer network between the PUR structure and the poly-AAAS. Polyurethane foams in museum collections already show, in some cases, severe degradation. Molecules formed during degradation could change the polarity of the PUR surface and promote or prevent AAAS penetration. For this reason, the treatment needs also to be tested on already degraded polyurethane foams.

For paper conservation, AAAS have already been used for deacidification and consolidation of degraded paper [16] [17]. The use of AAAS on a cellulosic degraded network provides an alkaline buffer, improves the mechanical resistance of the paper and remains effective even after artificial aging [18]. These previous researches suggest that AAAS could be appropriate also for the consolidation of already degraded PUR ester foam.

The present study investigates the possibility to consolidate with AAAS artificially degraded PUR ester foams. The samples have been previously degraded according to the conditions determined by Pellizzi et al. in a study on the artificial degradation of PUR ester foam $\left(90^{\circ} \mathrm{C}\right.$ and $50 \% R H$ during 3 weeks) [6]. The same PUR ester foam used for previous studies has been chosen because of the composition of the foam that is one of the most largely spread in museum collections (PUR ester foam made of 2,6- and 2,4toluenediisocyanates (TDI) and poly[di(ethylene glycol) adipate]). All the information already collected about the degradation of this particular foam will be useful to better investigate the possibility to consolidate this material. 
However, different isocyanates or polyols employed for the PUR formulation could have an influence on the affinity between the AAAS and the PUR and affect the penetration of the treatment and the final consolidation strength.

AMDES and DIAMINO treatments are applied on artificially degraded polyurethane foams and the effects of the two treatments compared. The application of the treatment is performed by immersion of the foam in a solvent that implies good wetting of the surfaces and homogeneous diffusion of the AAAS molecules inside the foam structure [15]. At first sight, considering that the cells of the foam are open, the foam cell size should not affect the application of the treatment. However, this point has to be checked and to be considered in the case of an application by spray or by nebulization that would be chosen for the treatment of a real work of art.

Colorimetric measurements, stress/strain compression curves, scanning electron microscopy (SEM) images, Fourier transform infrared (FTIR) spectra, and ${ }^{29} \mathrm{Si}$ magic angle spinning nuclear magnetic resonance $\left({ }^{29} \mathrm{Si} \mathrm{MAS}\right.$ NMR) spectra will be discussed to evaluate the effectiveness of the two AAAS treatments for artificially degraded PUR ester foam reinforcement. Finally, some recent ${ }^{29} \mathrm{Si}$ MAS NMR analysis performed on treated foams of four years old allowed to assess the stability of the AAAS treatment after four years of natural aging. These latest results are particularly relevant for the field of conservation science because very few publications exist on the monitoring and the stability of recently developed treatments. 


\section{Material and Methods}

\subsection{Samples and chemicals}

New Dimension Industries LLC (NDI LLC) supplied the PUR ester reference foam. It is an open-cell flexible PUR ester foam formulated with 2,6and 2,4- toluenediisocyanates (TDI) and poly[di(ethylene glycol) adipate], with a density of $30 \mathrm{~kg} / \mathrm{m}^{3}$. The foam was pre-cut by NDI LLC in cubic regular samples $(50 \mathrm{~mm} \times 50 \mathrm{~mm} \times 30 \mathrm{~mm})$ suitable for compression tests.

Hexamethyldisiloxane (HMDS) was the solvent employed for the AAAS monomer solutions. It was primarily chosen for its low cohesive energy density and low surface tension, that permit a good wetting of the sample surfaces, and secondly for its weak van der Waals interactions that assure a good dimensional stability of the sample structure after solvent evaporation. HMDS solvent, AMDES and DIAMINO monomers were provided by Abcr $\mathrm{GmbH}$. All the compounds were used as received from the producer, without further purification.

\subsection{Artificial aging}

Artificial aging in humid atmosphere has been realized in an aging chamber Vötsch Industrietechnik VC0020. These chambers can control temperature and humidity during the conditioning with a setting accuracy of $\pm 0,3^{\circ} \mathrm{C}$ for the temperature and of \pm 1 to $3 \% R H$ for relative humidity.

The aging conditions were determined on the basis of a previous study on the degradation of this particular type of foam [6]. The degradation level chosen correspond to the one of a PUR that is partially hydrolyzed but that is not yet crumbled. No treatment could be applied on an already 
crumbled foam because once the structure collapses there is no treatment that could reassemble the powder into a flexible foam. The artificially aged samples were then obtained by aging the foam at $90^{\circ} \mathrm{C}$ and $50 \% \mathrm{RH}$ during 3 weeks. The glass transition temperature $\left(\mathrm{T}_{g}\right)$ of the PUR was determined in a previous study and it is around $-40^{\circ} \mathrm{C}[6]$. It is worth noting that both ambient temperature and artificial aging temperature are far above the $\mathrm{T}_{g}$ of the polymer.

\subsection{PUR consolidation treatments}

Solutions of AMDES and DIAMINO in HMDS were prepared at different AAAS concentrations $(2.5 \%, 5 \%$ and $10 \% \mathrm{vol} / \mathrm{vol})$. The effect of HMDS solvent alone on artificially aged PUR ester foam was also evaluated. The samples were weighed and immersed for 24 hours in each solution using closed polypropylene containers. To avoid foam flotation, an aluminum grid fixed inside the polypropylene container was used to maintain the samples dipped into the solution. After immersion the samples were dried under vacuum for 6 hours at ambient temperature. Once completely dried they were weighed once more in order to determine the AAAS uptake. To insure the complete evaporation of the solvent, measurements were performed two weeks after treatment at the earliest.

\subsection{Colorimetric measurements}

The CIE $L^{*}, a^{*}$ and $b^{*}$ coordinates were measured with a portable sphere spectrophotometer X-Rite SP64 using the following set-up parameters: $4 \mathrm{~mm}$ measurement area $\left(6.5 \mathrm{~mm}\right.$ target window), illuminant type $D 65,10^{\circ}$ standard observer angle and specular component included (SPIN). The measure- 
ments were repeated on the top surface of 3 replicate samples at 5 different locations on each replicate. The mean values were used to calculate the total color difference $\Delta E_{a b}^{*}$ and the metric chroma difference $\Delta C_{a b}^{*}$ between the treated samples and the reference using the standard colorimetric equations according to the ASTM Standard D 2244-93 [19]:

$$
\begin{gathered}
\Delta E_{a b}^{*}=\sqrt{\left(\Delta L^{*}\right)^{2}+\left(\Delta a^{*}\right)^{2}+\left(\Delta b^{*}\right)^{2}}, \\
C_{a b}^{*}=\sqrt{\left(a^{*}\right)^{2}+\left(b^{*}\right)^{2}}, \\
\Delta C_{a b}^{*}=\left(C_{a b}^{*}\right)_{\text {treated sample }}-\left(C_{a b}^{*}\right)_{\text {reference }} .
\end{gathered}
$$

The foam flexible structure is easily deformed by the weight of the spectrophotometer when this is applied directly in contact with the sample upper surface, especially when the foam is degraded and its mechanical properties are modified. This deformation could affect the chromaticity coordinate value measurements [20] and damage the foam surface. To avoid any deformation of the foam cell structure, a rigid black box with a hole of $53 \times 53 \mathrm{~mm}$ on the top is used as an additional device to the spectrophotometer X-Rite. For the measurements, the samples are inserted in the central hole of the box. The portable spectrophotometer is then positioned onto the box in close contact with the foam surface and the analysis can be performed without any deformation of the foam cell structure (Figure 1). In addition to the deformation of the structure other parameters like the foaming expansion direction of the cells and the cell dimension could affect the measurement. For these reasons, 
to allow the comparison of the results, measurements have been done for all the samples on the same upper face of the cube.

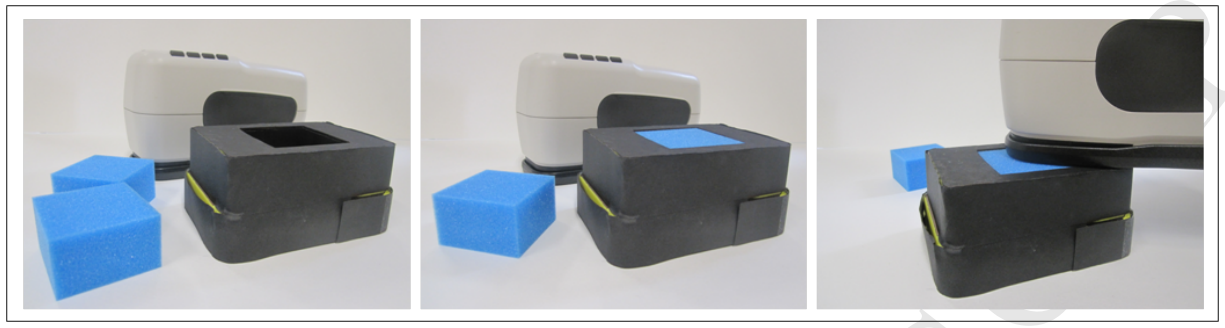

Figure 1: Images of the rigid black box used as an additional device during the colorimetric analysis with the portable sphere spectrophotometer X-Rite SP64

\subsection{Mechanical tests}

Mechanical properties have been studied by Compression Force Deflection Test according to the ASTM Standard D 3574-03 test C method [21] using an Adamel Lhomargy DY.20 B tensile/compression instrument. At least three specimens per sample were tested and the value reported is the mean value of those observed. Every specimen was compressed down to $50 \%$ of its thickness $(15 \mathrm{~mm})$ at $50 \mathrm{~mm} / \mathrm{min}$ and kept under compression for 60 seconds. The entire stress/strain curve was recorded and the final force after 60 seconds determined. The experimental setup was installed in a controlled atmosphere chamber at $50 \% \mathrm{RH}$ and $23^{\circ} \mathrm{C}$ and the samples were conditioned for at least 48 hours before the test.

\subsection{SEM imaging}

Backscattered electron images and Silicon (Si) surface elemental analysis of PUR foam before and after treatment were obtained with a Scanning 
Electron Microscope (SEM) Jeol JSM-5410LV equipped with an Oxford Link Isis - Energy Dispersive X-ray Spectrometer (EDS). Foam samples were cut with a scalpel blade in pieces of approximately $5 \mathrm{~mm} \times 3 \mathrm{~mm} \times 2 \mathrm{~mm}$ to fit in the SEM vacuum chamber. The cutting of the foam allowed thus to expose and visualize cross sections of the cell edges. The samples were mounted on aluminum sample holders with double-sided carbon tape (NEM tape, Nisshin EM Co. Ltd.) and coated with gold to a thickness of approximately $300 \AA$. The following experimental conditions were kept constant for both backscattered images and elemental analysis: high vacuum, $20 \mathrm{~mm}$ working distance, $20 \mathrm{kV}$ accelerating voltage.

\subsection{FTIR spectroscopy}

FTIR spectra were recorded on a Nicolet 6700 spectrophotometer, equipped with a diamond ATR macro-system (Smart Endurance) scanning from 600 to $4000 \mathrm{~cm}^{-1}, 36$ scans were recorded for each spectrum at a resolution of $8 \mathrm{~cm}^{-1}$. To obtain information about the treatment distribution and its homogeneity, treated samples were cut in slices allowing infrared analysis at different points of the sample thickness. Five spectra were collected from each sample; one from the top, one from the bottom and three from the bulk at regular intervals.

\section{8. ${ }^{29}$ Si MAS NMR}

Magic angle spinning nuclear magnetic resonance (MAS NMR) experiments were performed in $4 \mathrm{~mm}$ zirconium oxide rotors on a Bruker $A S X$ spectrometer with a $11.7 \mathrm{~T}$ magnetic field. 
${ }^{29} \mathrm{Si}$ one-pulse experiments $(99.4 \mathrm{MHz})$ were performed spinning at $7 \mathrm{kHz}$ with a radio-frequency pulse $(\pi / 2)$ duration of $4 \mu s, 20 s$ recycle time and between 3000 and 5000 acquisitions depending on the samples. Peak decomposition of the MAS NMR spectra were obtained using the Dmfit2011 software [22].

\section{Results and Discussion}

The properties of the artificially degraded PUR foam were compared before and after treatment with both AMDES and DIAMINO monomers. At the same time, a comparison was done between the treated artificially degraded PUR foam and the undegraded PUR foam. This observations were useful to evaluate the efficiency of the treatment in returning to the foam its original (pristine) properties.

\subsection{Influence of the treatment on the sample weight uptake}

Weight uptake values of artificially degraded PUR foams were measured two weeks after treatment to assure the complete evaporation of the solvent. Figure 2 shows the uptake values as a function of the AAAS concentration both for AMDES and DIAMINO treatments. Higher concentration of AAAS in solution resulted in larger uptakes.

We already highlighted the affinity between the PUR and the AAAS monomers in previous studies [23] [15], moreover the results obtained after consolidation of artificially degraded PUR foams showed that the affinity increased when the PUR foam was artificially degraded. This is probably due to the presence of degradation products on the PUR foam surface. The 


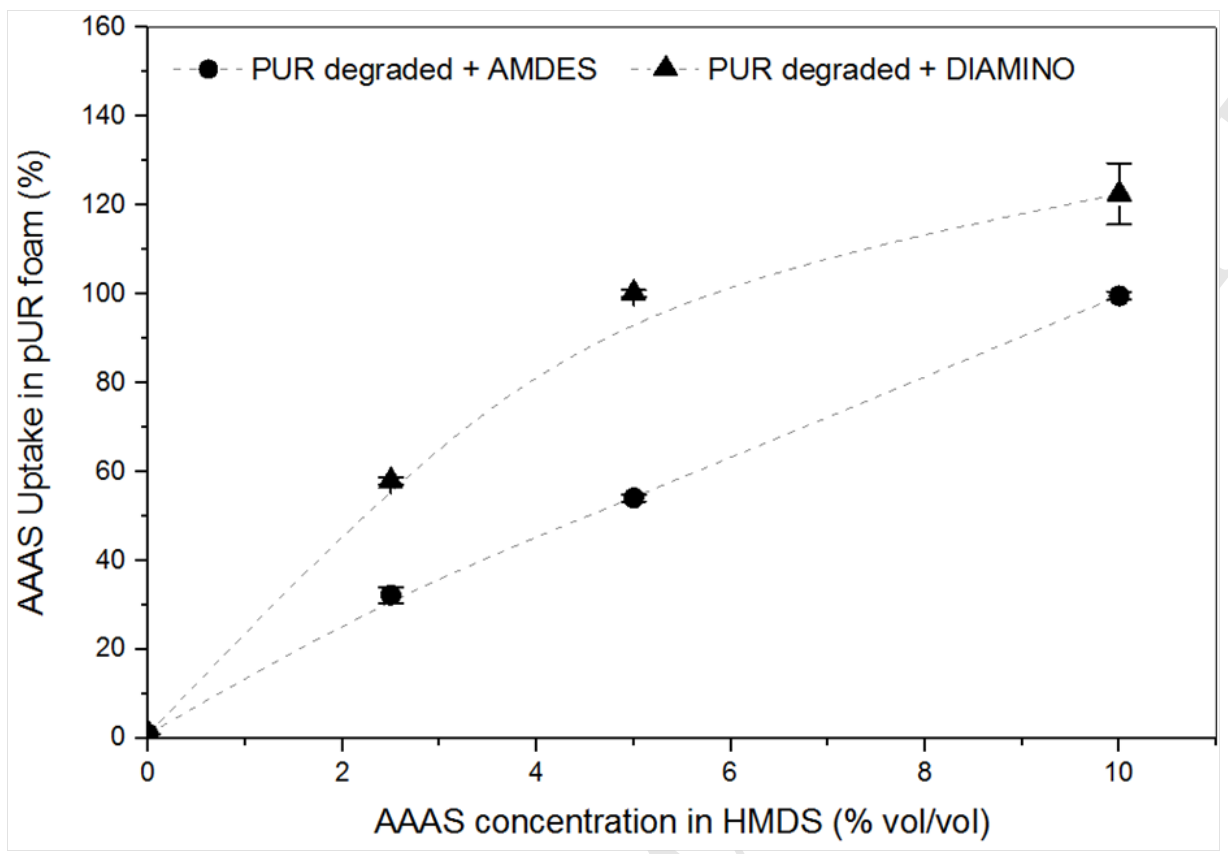

Figure 2: Uptake values for the artificially degraded PUR ester foam $(\% w t / w t)$ after treatment as a function of the concentration of AAAS in HMDS $(\% \mathrm{vol} / \mathrm{vol})$.

presence of these products (alcohols, carboxylic acids, etc...[6]) could have increased the amount of AAAS molecules absorbed by the foam.

\subsection{Influence of the treatment on the visual aspect of the foam}

An important issue for conservation treatments dealing with museum artifacts is the impact of the treatment on the color of the object treated. Most of the time it is important to minimize the color variation due to the addition of a new material. In the case of a degraded PUR, degradation reactions originate in the PUR molecular structure double bonds that absorb part of the visible radiation resulting in a visual yellowing of the foam. The color of a degraded foam is then different than the one of the undegraded 


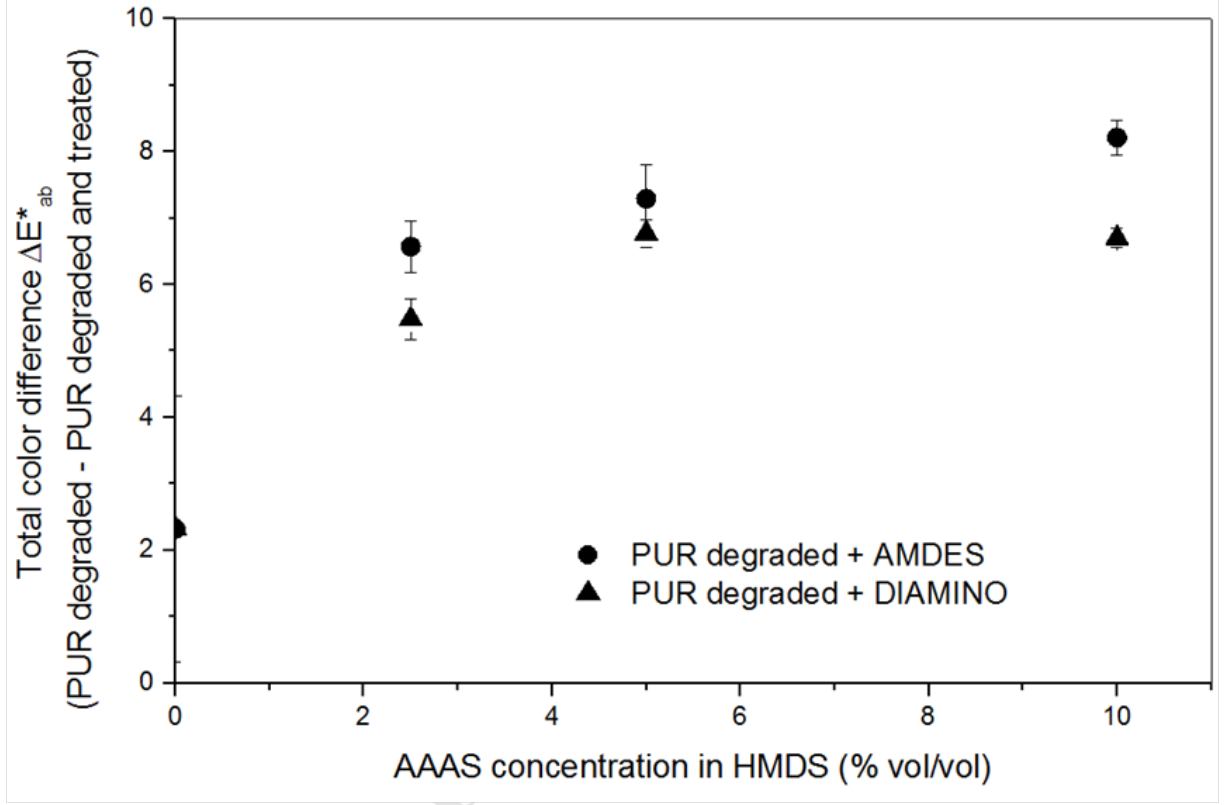

Figure 3: Total color difference $\Delta E_{a, b}^{*}$ between treated artificially degraded PUR samples from untreated artificially degraded reference as a function of the concentration of AAAS in $\operatorname{HMDS}(\% w t / w t)$. 


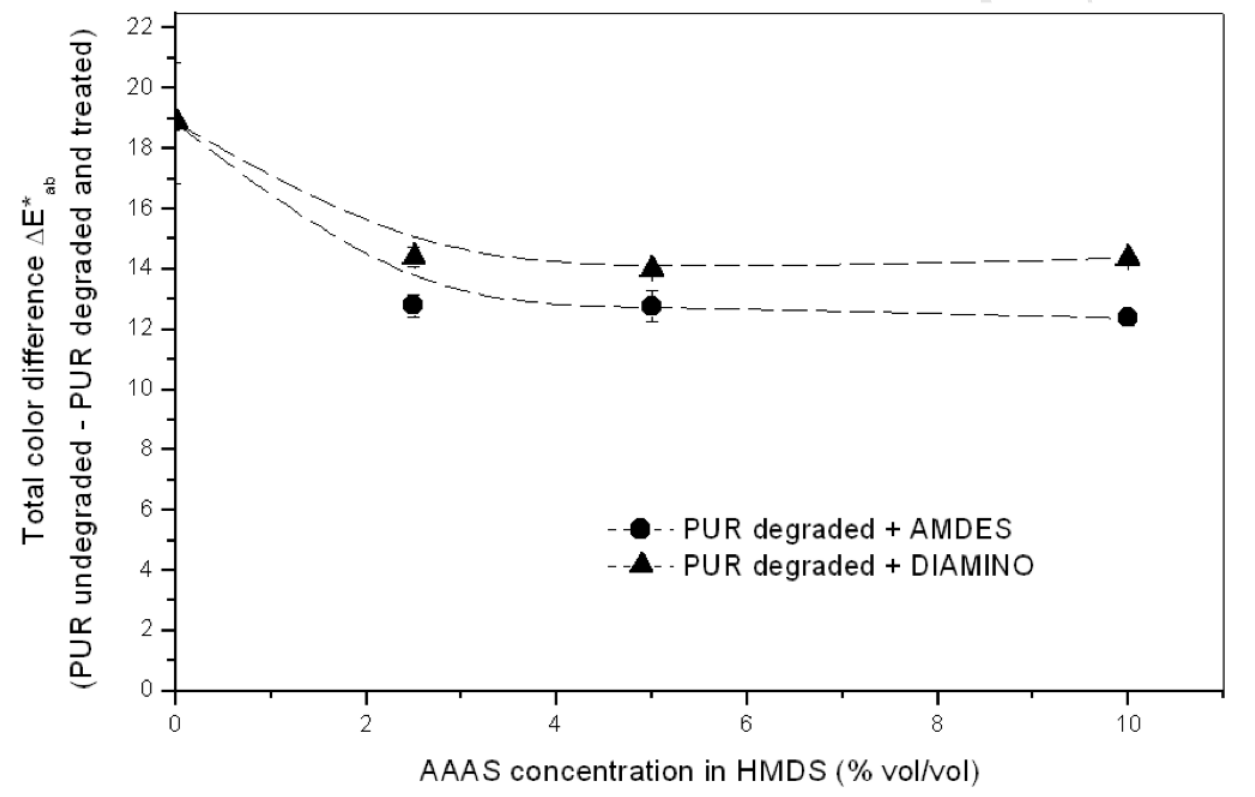

Figure 4: Total color difference $\Delta E_{a, b}^{*}$ between treated artificially degraded PUR samples from untreated undegraded reference as a function of the concentration of AAAS in HMDS $(\% w t / w t)$. 
original foam. Regardless, even for already degraded samples the treatment should preserve the color of the foam before its application: the addition of a new material has to limit as far as possible the visual modification of the object.

The total color difference $\Delta E_{a, b}^{*}$ between the treated samples and the artificially degraded reference, calculated as in equation (1), is shown in Figure 3 for both AMDES and DIAMINO treatments. Even without AAAS, the treatment of the foam with HMDS solvent alone resulted in a $\Delta E_{a, b}^{*}$ color difference of 2.25 units. Anyway, this difference did not result in a perceptible color change. Color difference values between samples treated with AAAS and the artificially degraded reference were in the range of 5.0 and $8.0 \Delta E_{a, b}^{*}$ units. These $\Delta E_{a, b}^{*}$ values resulted in color variations perceptible to the naked eye when the samples were placed one next to the other under natural light. As for the treatment applied to undegraded PUR (discussed in Pellizzi et al. [15]), larger color difference values corresponded to higher AAAS concentration in HMDS solution. DIAMINO treated samples showed color difference values from the artificially aged reference slightly larger than AMDES treated samples. This has to be related to the larger uptake values obtained for the samples treated with DIAMINO solutions (see section 3.1).

$\Delta E_{a, b}^{*}$ values obtained between treated artificially degraded PUR samples and the undegraded reference showed that the total color difference value decreased after treatment of the samples (Figure 4). This result means that the color appearance of an artificially degraded foam after treatment have been shifted toward the original color of the undegraded foam. This variation was highlighted by a decreasing of the yellowing of the foam (due to the 
decreasing of $b$ values measured). The treatment influenced the color of the artificially aged foam in a perceptible way. This might be acceptable since, in this particular case, after consolidation the foam color was closer to the original color of an undegraded foam. A possible explication for the decreasing of the yellowing is the probable reaction of the AAAS monomers with some of the degradation products of the foam. The occurrence of such reactions is supported by the the fact that the uptake after treatment was more important for an artificially aged foam than for an undegraded one (see section 3.1), demonstrating that the absorption of AAAS monomers on polyurethane surface is greater when degradation products are present.

\subsection{Influence of the treatment on the mechanical properties of the samples}

The main goal of this study was to develop a treatment to reinforce a degraded PUR ester foam structure and avoid the cell collapse under stress. The evaluation of the mechanical properties evolution before and after treatment was then a determining point to investigate. Compression force deflection test (ASTM D 3574-03) has been used to evaluate the mechanical properties evolution of PUR ester artificially degraded foam after AAAS treatment.

Polyurethane depolymerization induced by artificial degradation (hydrolysis) is the cause of the foam structure collapse under stress [6]. When a stress is applied on a degraded foam the structure collapse and the cell edge fracture inhibits the recovery of the structure. Compression test after AAAS treatment provided a measure of the mechanical recovery of the structure after stress removal. All the samples treated were able to recover $100 \%$ of their thickness after compression. This means that when one of the two AAAS monomers is applied on a degraded foam the treatment avoid the cell 
collapse giving back a certain elasticity to the foam structure.

The acquisition of stress-strain curves allowed to investigate further the new properties of treated samples. In Figure 5 and Figure 6, stress-strain curves of treated samples and of the two untreated references are reported. The two references are the undegraded polyurethane (gray curve) and the artificially degraded polyurethane (red curve) without any treatment. The red curve describes the mechanical properties of the artificially degraded samples before treatment, and the gray curve describes the mechanical properties that the AAAS treatment should ideally be able to restore.

All the curves obtained exhibit a first domain with a linear elastic behavior which ends with a limit load maximum (yield strength). This first linear part is followed by a large plateau which involves plastic deformation.

After AMDES based treatment (Figure 5), the curves of the samples showed a slight stiffening effect on the initial modulus, the slope of the curve between 0 and $0.05 \mathrm{~mm} / \mathrm{mm}$ becoming steeper. They also showed a small increase of the maximum load as the stress at yield point increases. This results in slightly stiffer materials more resistant to compression. The area under the stress-strain curve is the strain energy per unit volume absorbed by the material and the integration value of this area is a measure of the sample toughness. For all treated samples the whole stress plateau moved to higher stress values, increasing the area under the curve and therefore the whole toughness. However, the stress plateau of an artificially degraded polyurethane treated with AMDES did not approach the stress value of an undegraded foam. In conclusion, AMDES treated samples were able to recover their original thickness after compression but their stress-strain behav- 


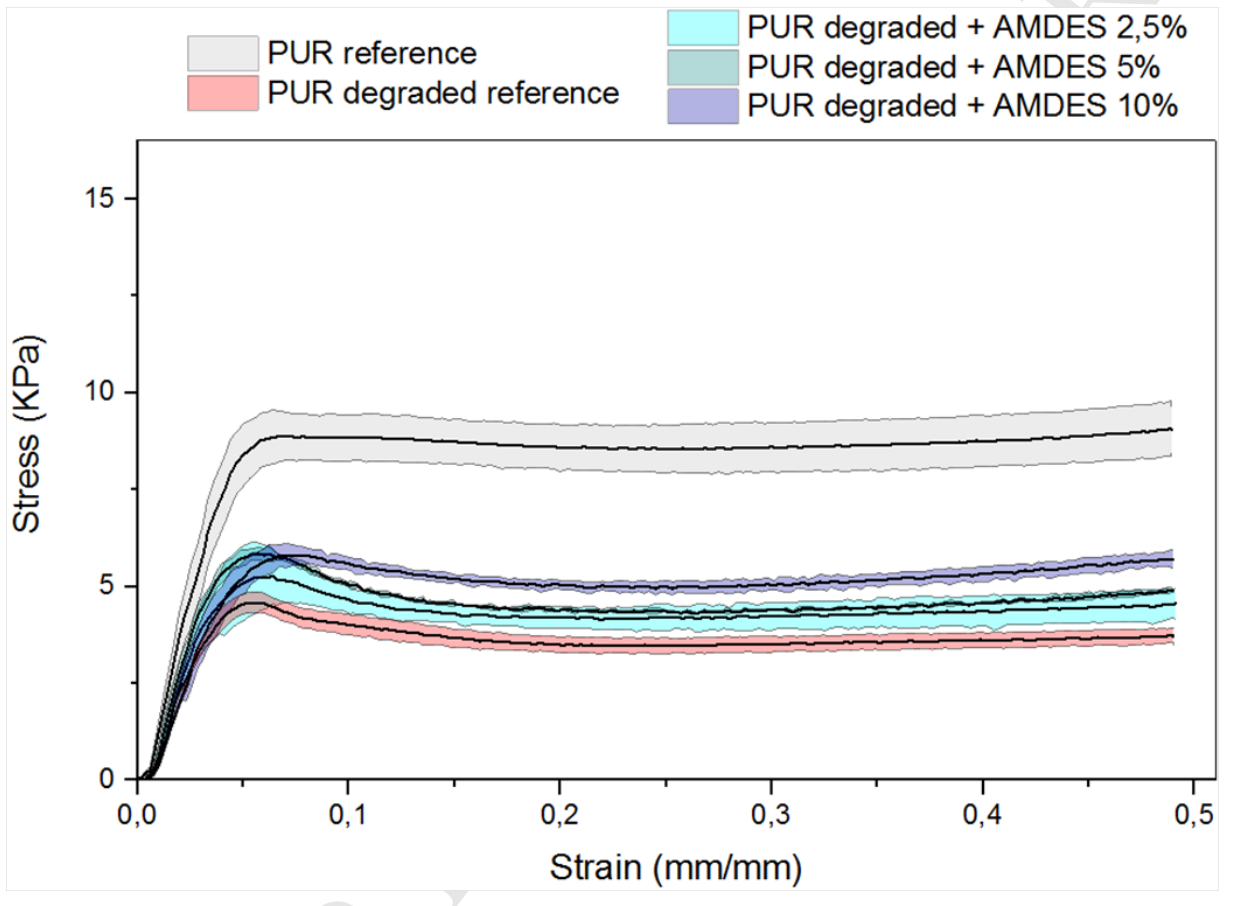

Figure 5: Stress-strain curves of AMDES treated samples at different concentration of AMDES in HMDS solvent. Black lines correspond to the mean stress-strain curves obtained considering all replicates for each sample. Colored shadows represent the standard deviation at each point of the curve. 


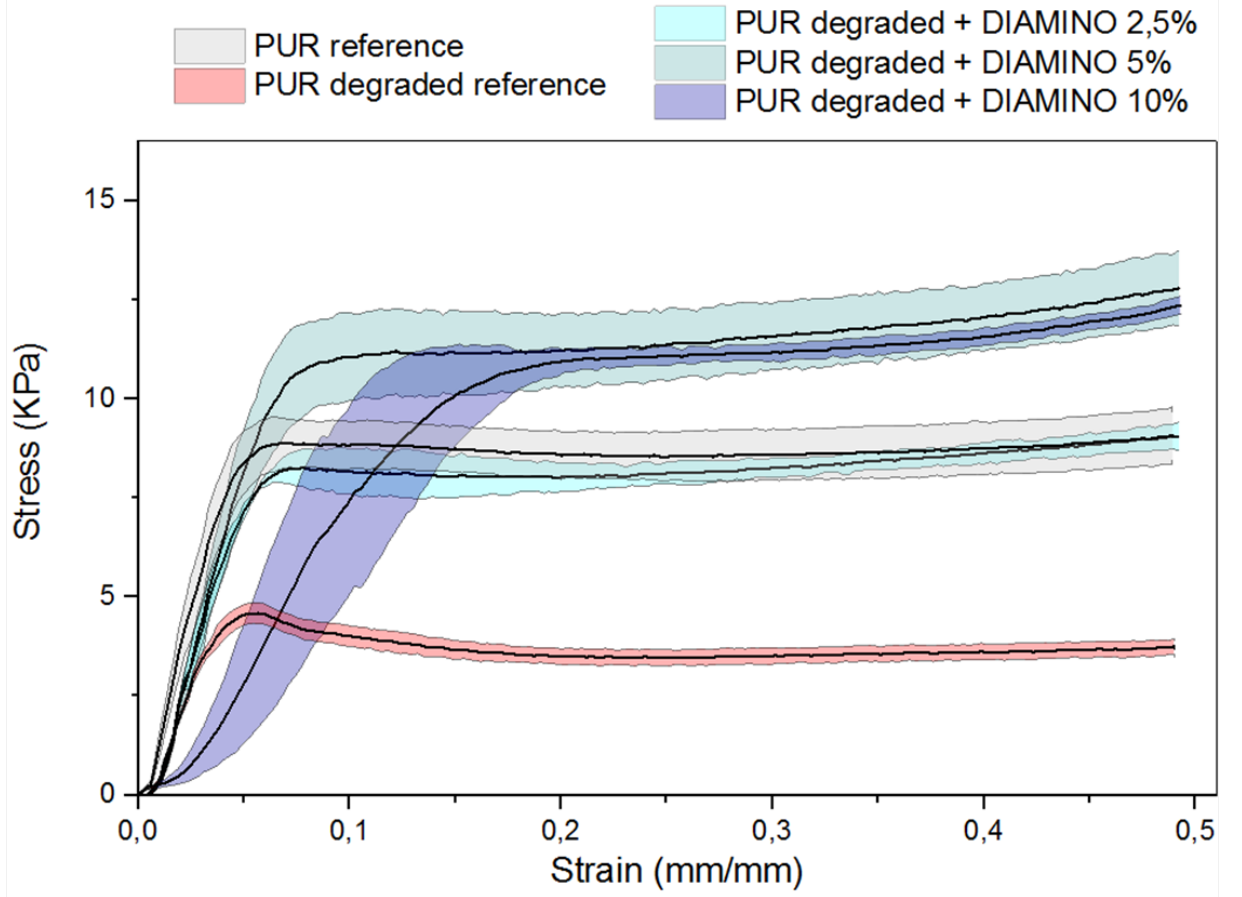

Figure 6: Stress-strain curves of DIAMINO treated samples at different concentration of DIAMINO in HMDS solvent. Black lines correspond to the mean stress-strain curves obtained considering all replicates for each sample. Colored shadows represent the standard deviation at each point of the curve. 
ior showed that they remained weaker than the undegraded polyurethane foam.

In contrast, after DIAMINO based treatment (Figure 6), the degraded foams increased their toughness up to the toughness of the undegraded reference and even beyond. The samples treated with solutions of DIAMINO 2.5\% and 5\% increased also their stiffness, while samples treated with DIAMINO at $10 \%$ showed a decreasing of the slope of the curve between 0 and $0.2 \mathrm{~mm} / \mathrm{mm}$, meaning that the treatment gave the foam more flexibility. The treatment that gave the best result is the one obtained using the DIAMINO solution at $2.5 \%$. In these conditions, the recovering properties of the foam were restored, avoiding the cell collapse, and the stress strain curve obtained described a mechanical behavior very close to the one of an undegraded foam.

\subsection{Penetration and polymerization of the treatment}

SEM microscopical observation allowed the investigation of the treatment penetration into the foam structure, while FTIR spectroscopy and ${ }^{29} \mathrm{Si}$ MAS NMR spectroscopy gave information about the polymerization of AAAS monomers within the PUR foam.

SEM low magnifications images were recorded to visualize changes in the foam structure and differences on the PUR cell surfaces, while high magnification images permitted to investigate whether an AAAS penetration within the cell edges was present. Figure 7 shows the backscattered image of an artificially degraded reference sample (a) in comparison with a artificially degraded DIAMINO treated sample (a'), and the respective Si SEM-EDS mapping (b, b')(magnification x35). From the backscattered image of treated 
artificially degraded PUR foam (Figure $7 a^{\prime}$ ) DIAMINO deposit appears to be homogeneously distributed as a film that does not fill the cell voids. Si SEM-EDS mapping, which permitted to obtain a map of the Si distribution, has then be used to verify it. From the Si EDS map (Figure $7 b, b^{\prime}$ ), $\mathrm{Si}$ is detected overall the foam cell surfaces of the treated sample $\left(b^{\prime}\right)$, this confirmed the existence of a coating that cover completely the inner foam structure. AMDES and DIAMINO coatings had the same aspect.

Penetration of AAAS inside the foam edges has been investigated by Si SEM-EDS mapping as well (magnification x750). Figure 8 shows the backscattered image and the Si cartography of a PUR edge cross section prepared from a degraded PUR foam treated with DIAMINO. The backscattered image (Figure $8 a$ ) shows the triangular cross section of one of the edges. On the Si EDS map (Figure 8 b), Si is detected in the $10 \mu m$ near the cross section borders. This result proved that the treatment diffused partially inside the cell edges and consequently an interpenetrating polymer network between the PUR structure and the AAAS polymer chains has been obtained. Several images from both AMDES and DIAMINO treated samples have been recorded and for all of them Si was detected inside the foam cell edges.

The same result was obtained in the previous study on the consolidation of undegraded foams [15], but penetration appeared to be slightly greater for artificially degraded PUR. Higher penetration of AAAS in already degraded PUR foam edges contributed to larger uptake values obtained for these kind of samples (see Section 3.1) and confirmed that the presence of degradation products probably increases the amount of AAAS molecules absorbed by the 
foam. A slight decrease of the cross-linking density may also play a role.

The distribution of the AAAS polymeric film in the thickness of the whole cubic sample has been estimated by repeating ATR-FTIR analysis at different points in the sample thickness from the top to the bottom. The ratio of Si- $\mathrm{CH}_{3}$ absorption band at $1257 \mathrm{~cm}^{-1}$ to the $\mathrm{C}=\mathrm{O}$ ester absorption band at $1727 \mathrm{~cm}^{-1}$ has been considered as an indicator of the AAAS concentration as discussed in a previous publication [15]. On all ATR-IRTF spectra the band at $1003 \mathrm{~cm}^{-1}$, corresponding to Si-O-Si stretching, appeared after treatment of artificially degraded samples. This proved that polymerization of AAAS monomers occurred on all treated samples.

In Figure 9 and Figure 10 the ratio $\mathrm{Si}-\mathrm{CH}_{3} / \mathrm{C}=\mathrm{O}$ is plotted as a function of the position of the analysis in the sample thickness both for AMDES and DIAMINO treated samples. For both treatments, the $\mathrm{Si}-\mathrm{CH}_{3} / \mathrm{C}=\mathrm{O}$ ratio increased as the concentration of AAAS in solution increased. Moreover Si$\mathrm{CH}_{3} / \mathrm{C}=\mathrm{O}$ values were higher for samples treated with DIAMINO, confirming that after DIAMINO treatment the amount of polymer deposited on the degraded foam was higher than after AMDES treatment. The data showed that, when the treatment was applied to artificially degraded PUR foams, $\mathrm{Si}-\mathrm{CH}_{3} / \mathrm{C}=\mathrm{O}$ values were higher near the top and the bottom of the foam samples. This means that higher amount of AAAS was deposited in the proximity of the external surfaces of the cubic sample. This non-homogeneous distribution can be a consequence of the artificial degradation process applied to the foam. During artificial degradation the external surfaces of the cubic sample degrade slightly faster than its inside and this difference is probably at the origin of the higher concentration of AAAS near the more degraded 

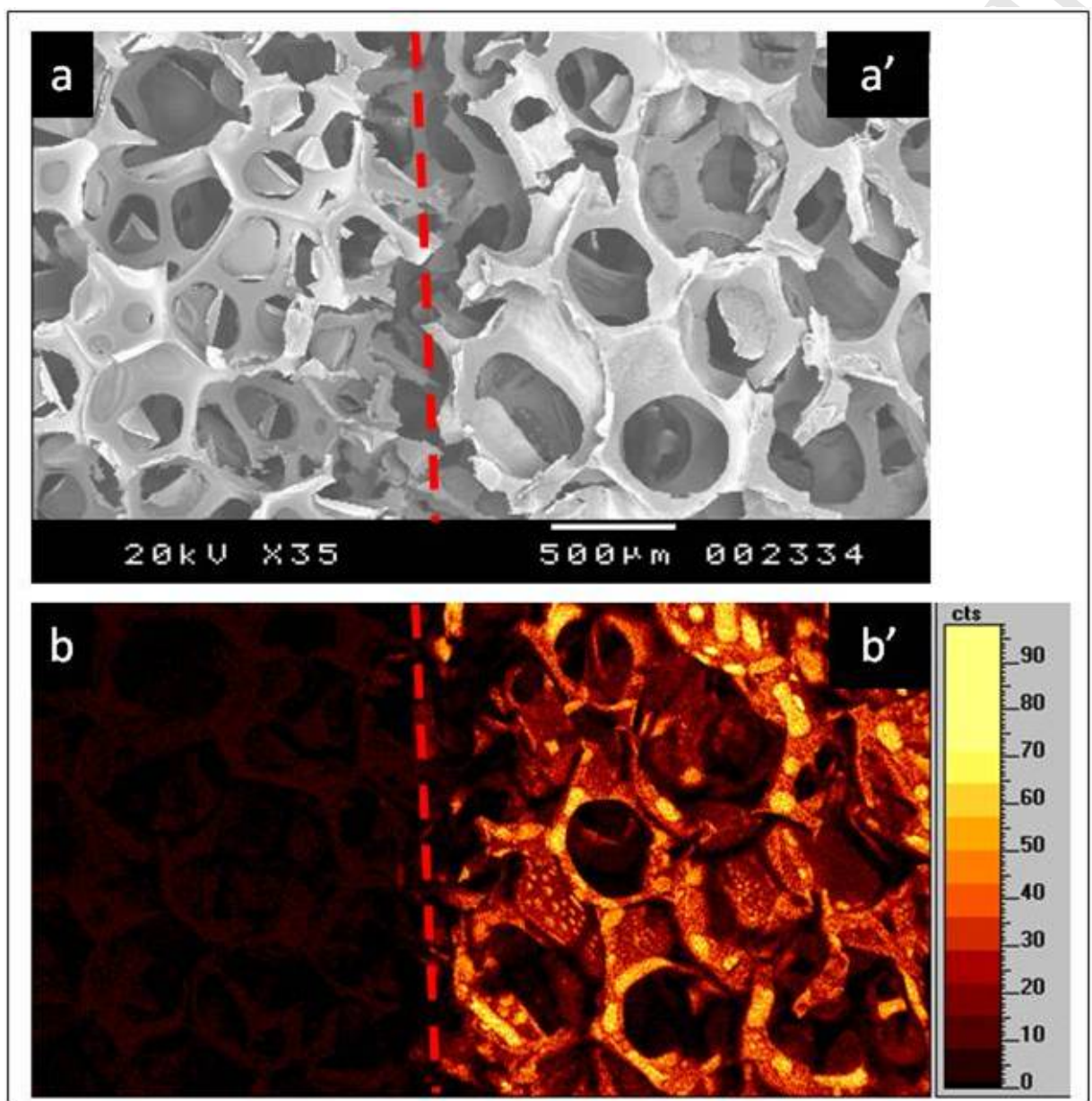

Figure 7: SEM backscattered images $\left(a, a^{\prime}\right)$ and Si EDS mapping $\left(b, b^{\prime}\right)$ of PUR ester reference foam $(a, b)$ and PUR ester DIAMINO treated $\left(a^{\prime}, b^{\prime}\right)$ (magnification x35) 


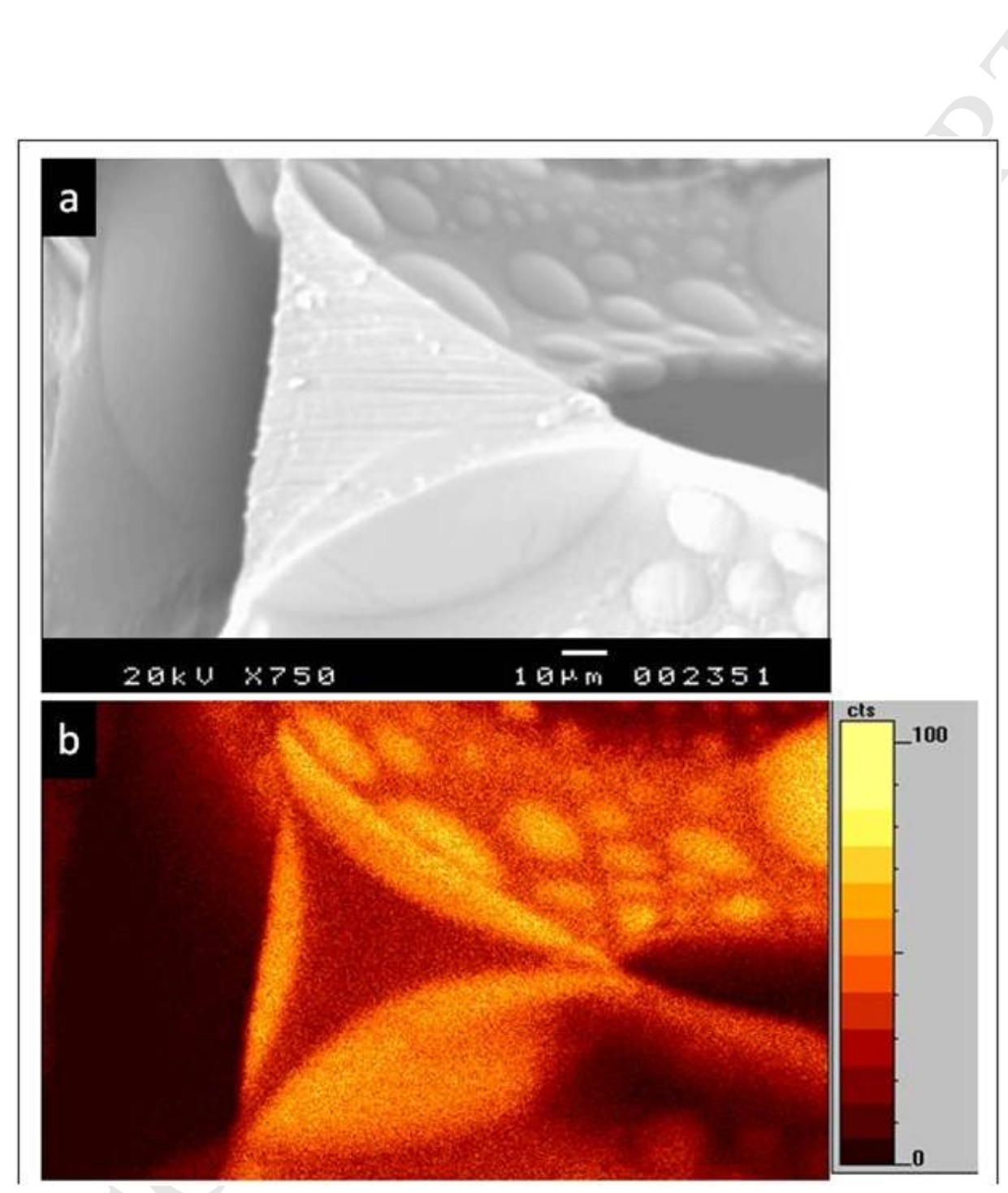

Figure 8: SEM backscattered images $(a)$ and Si EDS mapping (b) of a branch section in a PUR ester DIAMINO treated (magnification x750) 


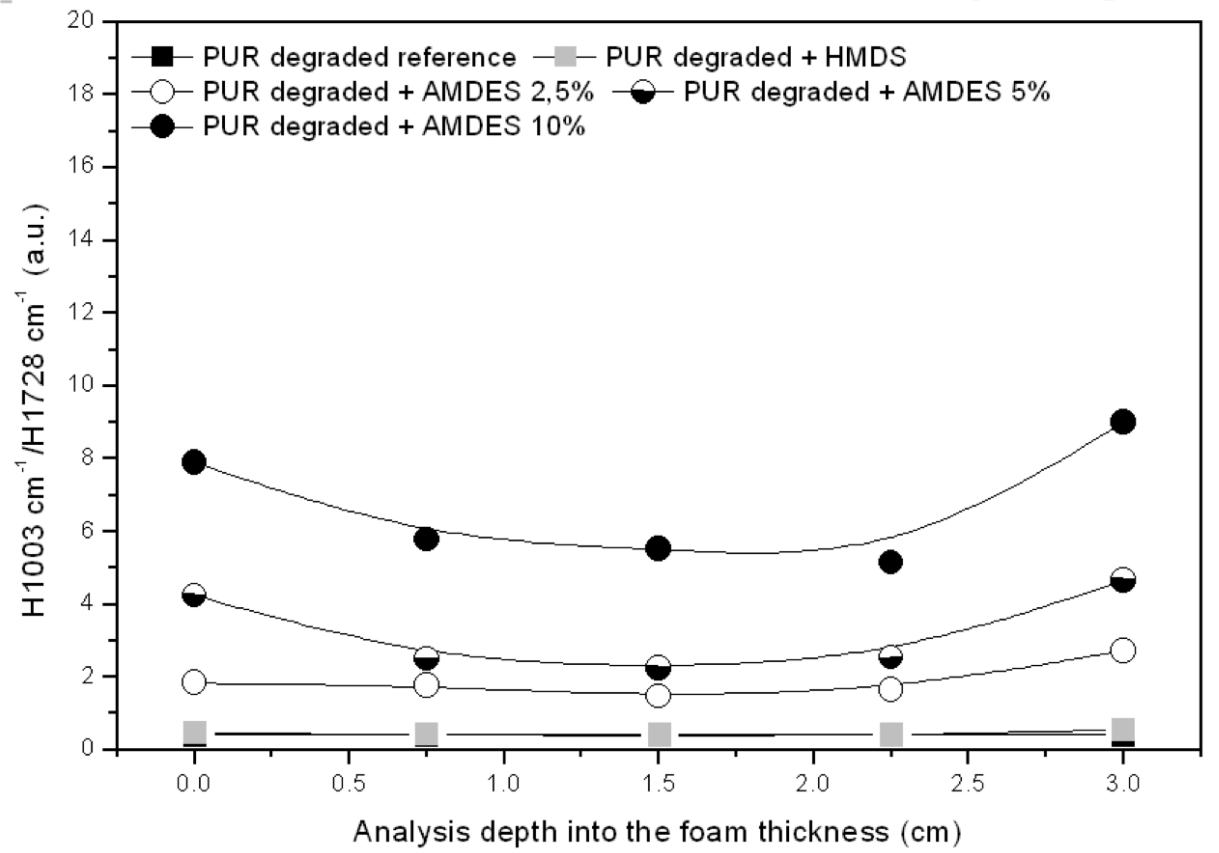

Figure 9: AMDES relative quantification (ratio of AMDES Si-CH 3 absorption band to PUR ester $\mathrm{C}=\mathrm{O}$ absorption band) plotted as a function of the depth of analysis ( 0 corresponds to the top of the sample and 3 corresponds to the bottom) 


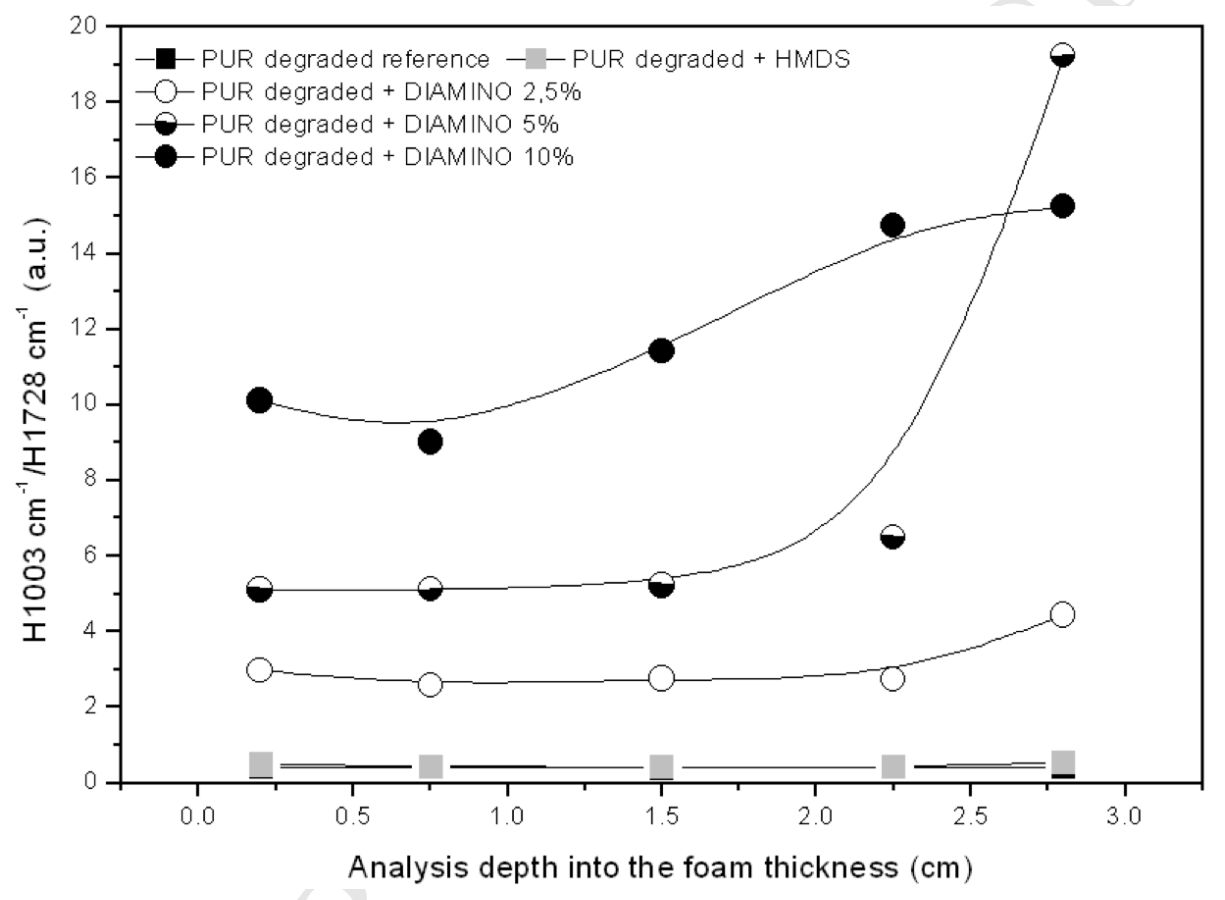

Figure 10: DIAMINO relative quantification (ratio of DIAMINO Si- $\mathrm{CH}_{3}$ absorption band to PUR ester $\mathrm{C}=\mathrm{O}$ absorption band) plotted as a function of the depth of analysis (0 corresponds to the top of the sample and 3 corresponds to the bottom) 
surfaces where higher concentration of degradation products is present.

It has to be considered that, at this point of the research, the consolidant can penetrate the entire volume of the foam only if the sample is entirely immersed in the consolidation solution. For a real work of art the immersion of the object is not conceivable, an application of the consolidant by spray or by nebulization would be more suitable. Nevertheless in this case the distribution of the consolidant would be less homogeneous and, in the case of a thick object the penetration would be limited. Some application tests have already been done by Royan et al. [26] however further investigations are needed to optimize the application for larger objects.

All the data collected proved that DIAMINO treatment is the one that gave better results in term of consolidation of degraded PUR foams, for this reason samples treated with DIAMINO have been chosen to investigate the polymerization degree of the AAAS polymer by ${ }^{29} \mathrm{Si}$ MAS NMR.

The ${ }^{29}$ Si MAS NMR spectra of the poly-DIAMINO reference shows four peaks at $-8,-16,-19$ and -22 ppm (Figure 11 - black line). These signals have already been attributed in previous studies: the peak at $-22 \mathrm{ppm}$ corresponds to $D_{2} \mathrm{Si}$, which is a silicon atom linked to two -O-Si substituents, the peak at $-19 \mathrm{ppm}$ corresponds to $\mathrm{D}_{4}$ cyclic tetramer, the peak at $-16 \mathrm{ppm}$ corresponds to $D_{1} \mathrm{Si}$ linked to only one -O-Si group, which is a terminal silicon atom and the peak at -8 corresponds to $D_{3}$ cyclic trimer [15] [24] [25]. From the integration of the two peaks at -16 and $-22 \mathrm{ppm}$ the value of number-average degree of polymerization $\left(\overline{D P_{n}}\right)$ of the linear polymer has been calculated for poly-DIAMINO as previously published [15]. The results showed that, for poly-DIAMINO deposed on degraded PUR foam, chains of 


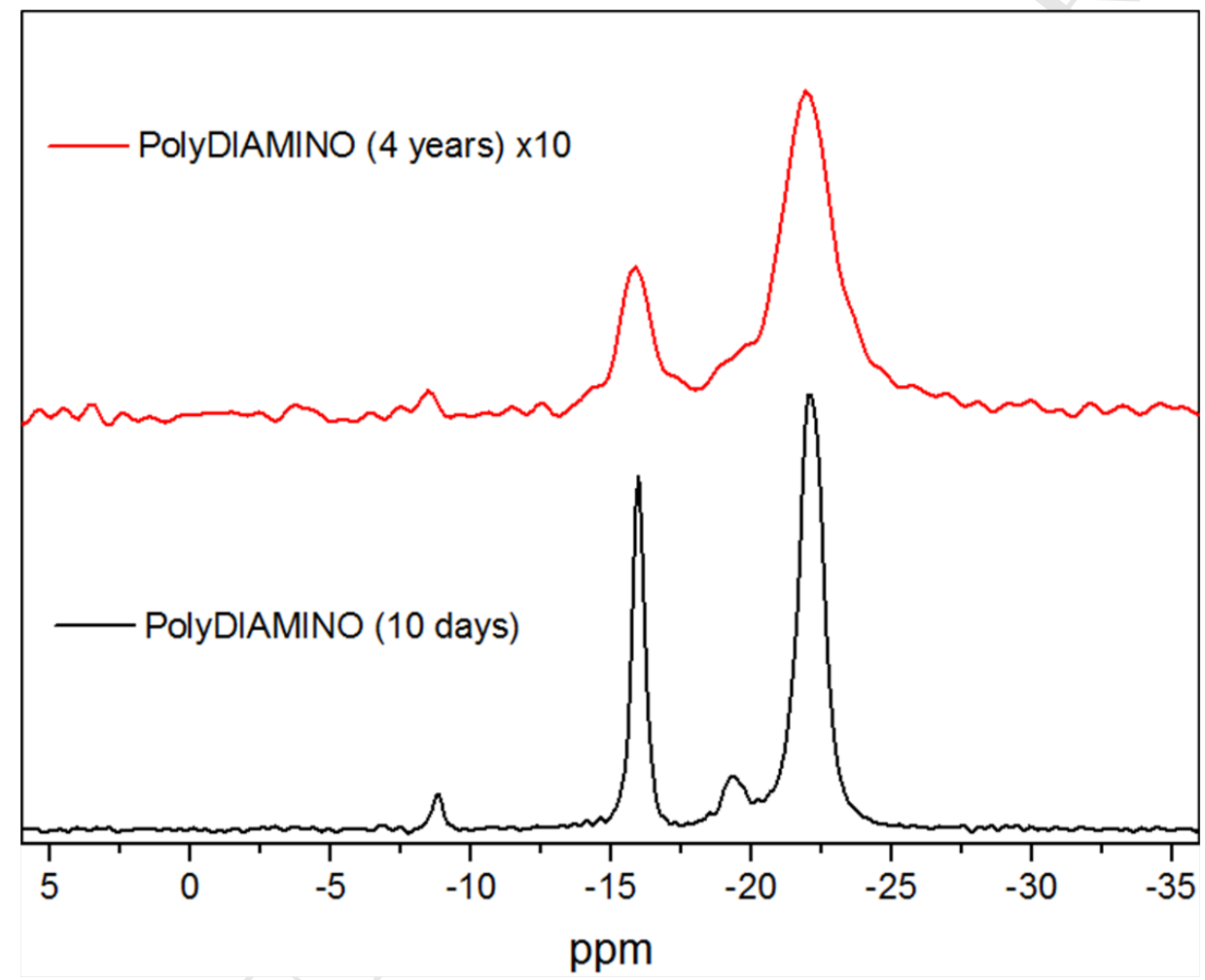

Figure 11: ${ }^{29} \mathrm{Si}$ MAS NMR spectra of a 10 days poly-DIAMINO sample (black line) and a poly-DIAMINO of 4 years old (red line) 
about 10 to 20 monomers units on average have been obtained. This result is similar to the one obtained for poly-DIAMINO deposed on undegraded PUR foams [15].

\subsection{Behavior of the treatment after four years of natural aging}

At the end of this study the authors had the possibility to repeat the ${ }^{29} \mathrm{Si}$ MAS NMR analysis on some samples after four years of natural aging. The results allowed to investigate the behavior of the poly-AAAS treatment in time. In Figure 11 two ${ }^{29} \mathrm{Si}$ MAS NMR spectra of polyDIAMINO are compared, the black one is obtained from a poly-DIAMINO samples just polymerized (after 10 days) and the red one is from a poly-DIAMINO of 4 years old. The $\overline{D P_{n}}$ values obtained from the integration of the peaks of these two spectra showed that DIAMINO monomers polymerized in the first 10 days forming polymer chains of about 7 monomer units, hereafter the polymer chain length remained rather stable giving polymer chains of 10 monomer units after 4 years of natural aging.

Table 1 reports $\overline{D P_{n}}$ values obtained from the poly-DIAMINO reference sample and different samples treated with DIAMINO within one year from the treatment, and $\overline{D P_{n}}$ values obtained after 4 years of natural aging. During the first campaign of ${ }^{29} \mathrm{Si}$ MAS NMR analysis degraded PUR treated samples were not analyzed, for this reason in Table 1 only values for undegraded PUR treated samples are reported for the first year from the treatment. The results show that after four years of natural aging the $\overline{D P_{n}}$ values did not change significantly both for the poly-DIAMINO reference and the poly-DIAMINO applied on PUR foam samples. 
Table 1: Poly-AAAS $\overline{D P_{n}}$ values of the linear polymer obtained within one year from the treatment and after 4 years of natural aging from different samples

\begin{tabular}{lcc} 
Sample name & \multicolumn{2}{c}{$\overline{D P_{n}}$ values } \\
& Within one year & After 4 years \\
\hline Poly-DIAMINO & 7,2 & 10,5 \\
PUR degraded + DIAMINO 2,5\% & - & 10,5 \\
$*$ PUR + DIAMINO 2,5\% & 12,6 & 14,2 \\
PUR degraded + DIAMINO 10\% & - & 18,7 \\
${ }^{*}$ PUR + DIAMINO 10\% & 18,4 & 19,1 \\
\hline
\end{tabular}

* Samples from Pellizzi et al. [15]

\section{Conclusions}

The ability of two different AAAS (AMDES and DIAMINO) to restore the mechanical properties of the foam structure of degraded polyurethane ester has been investigated. The two treatments have been applied by immersion on artificially degraded samples representative of naturally aged samples partially hydrolyzed but not yet crumbled. The foam structure of these artificially degraded samples collapse completely when a load is applied and the structure is compressed.

The results obtained after treatment showed that all samples are able to recover $100 \%$ of their thickness after compression. Therefore both treatments avoid the foam cell collapse giving back a certain elasticity to the foam structure. Mechanical tests showed as well that the treatment that gives the best results is the one obtained using the DIAMINO solution at 2.5\% in HMDS. In these conditions the recovering properties of the foam are restored and the stress strain curve obtained describes a mechanical behavior very close to the 
one of an undegraded PUR ester foam of the same type. Si SEM-EDS mapping made clearly visible the penetration of AAAS treatment inside the foam cell edges. This result confirms the creation of an interpenetrating polymer network responsible for the efficient reinforcement of the whole structure.

Furthermore, AAAS based treatments do not fill the cell voids of the foam preserving the original structural aspect of the samples. The visual aspect of the artificially aged samples after treatment is modified: a decreasing of the yellowing of the foam is observed. This results in PUR foam samples whose color is closer to the original color of the undegraded foam.

The behavior of the treatment in time as been investigated as well. The polymer chain length of the poly-AAAS applied on both unaged and artificially aged foams has been checked after four years of natural aging and the results showed that the $\overline{D P_{n}}$ values remain constant. This result gives a significant information on the stability of these kind of treatment, especially for the use of these products in the case of artworks conservation treatments. The study proved that the length of the poly-AAAS chains deposited on the PUR foams samples is not modified after 4 years of natural aging.

The aim of this study was to asses the possibility to use AAAS based treatments to consolidate already degraded PUR ester foam objects in museum collections. In conclusion, the results demonstrate that especially a DIAMINO based treatment could be a valuable method to restore flexible degraded PUR ester foam mechanical properties and to extend the life of these kind of objects.

A first application of the DIAMINO treatment on a real artwork has already been realized. An object made of PUR foam which is part of a 
Ben Vautier's artwork conserved at the Musée d'Art Moderne de la Ville de Paris, has been treated in 2013 [26]. The choice of applying the treatment was taken because of the poor state of conservation of the object that had to be replaced if no treatment was attempted. In the preliminary study carried out before the treatment of the work of art AAAS have been applied on both open cell and close cell PUR ester foam. The results confirmed that the treatment penetrates only when applied on open cell foams [26].

The actual good state of conservation of this object treated and exposed at the Musée d'Art Moderne de la Ville de Paris combined with the results of this study prove that these treatments could became an effective solution for the conservation of degraded PUR ester foam artworks.

\section{Acknowledgments}

The present research has received funding from the European Community's Seventh Framework Program F P7/2007 - 2013 under the grant agreement no.212218 - POPART: Strategy for the preservation of plastic artifacts in museum collections.

\section{Bibliography}

[1] Quye, A., Williamson, C.. Plastics: collecting and conserving. Edinburgh: NMS Pub.; 1999.

[2] Waentig, F.. Plastics in art: a study from the conservation point of view. Petersberg: Imhof; 2008. Originally published as: Kunststoffe in der Kunst. [English translation, Michael Scuffil]. 
[3] Szycher, M.. Szycher's handbook of polyurethanes. Boca Raton: CRC Press LLC; 1999.

[4] Kerr, N., Batcheller, J.. Degradation of polyurethanes in 20th-century museum textiles. In: Grattan, D.W., editor. Saving the Twentieth Century: The Conservation of Modern Materials. Canadian Conservation Institute; 1993, p. 189-206.

[5] Wilhelm, C., Gardette, J.L.. Infrared analysis of the photochemical behaviour of segmented polyurethanes: 1. aliphatic poly(ester-urethane). Polymer 1997;38(16):4019-4031.

[6] Pellizzi, E., Lattuati-Derieux, A., Lavédrine, B., Cheradame, H.. Degradation of polyurethane ester foam artifacts: Chemical properties, mechanical properties and comparison between accelerated and natural degradation. Polymer Degradation and Stability 2014;107(0):255-261.

[7] Lorne, A.. Experiments in the conservation of a foam object. In: Hummelen, I.M.C., Sille, D., editors. Modern art - who cares?: an interdisciplinary research project and an international symposium on the conservation of modern and contemporary art. Archetype; 1999, p. $143-148$.

[8] Rodrigo, E., Beerkens, L., Oosten, T.v., Keune, P.. Henk peeters 5918. In: Hummelen, I.M.C., Sill, D., editors. Modern art - who cares?: an interdisciplinary research project and an international symposium on the conservation of modern and contemporary art. Archetype; 1999, p. $43-51$. 
[9] Oosten, T.v.. Crystals and crazes: degradation in plastics due to microclimates. Munchen: Siegl; 2002, p. 80-89. In: T. van Oosten, Y. Shashoua, F. Waentig (Eds.), Plastics in art: history, technology, preservation.

[10] Lovett, D., Eastop, D.. The degradation of polyester polyurethane: preliminary study of 1960s foam-laminated dresses. In: Roy, A., Smith, P., editors. Modern art, new museums: contributions to the IIC Bilbao Congress, 13-17 September 2004. International Institute for Conservation of Historic and Artistic Works; 2004, p. 100-104.

[11] Colombini, A., Corbin, G., Leal, V.. Les materiaux en polyurethanne dans les oeuvres d'art : des fortunes diverses. Cas de la sculpture "Foot Soldier" de Kenji Yanobe. 2008. CeROArt http://ceroart.revues.org/432.

[12] Oosten, T.v., Lorne, A., Béringuer, O.. PUR Facts: Conservation of Polyurethane Foam in Art and Design. Amsterdam University Press; 2011.

[13] Oosten, T.v.. Research into the influence of impregnating agents on the aging of polyurethane (PUR) foams using FTIR spectroscopy. In: Picollo, M., editor. Proceedings of the sixth Infrared and Raman Users Group Conference (IRUG6): March 29th-April 1st, 2004. Il Prato; 2005, p. $155-161$.

[14] Pellizzi, E., Lattuati-Derieux, A., Lavédrine, B.. 4.3.3 Aminolakylalkoxysilane consolidation. Paris: Editions du CTHS; 2012, p. 281-287. 
In Preservation of Plastic Artefacts in Museum Collections, Edited by Bertrand Lavdrine, Alban Fournier and Graham Martin.

[15] Pellizzi, E., Lattuati-Derieux, A., d'Espinose de Lacaillerie, J.B., Lavédrine, B., Cheradame, H.. Reinforcement properties of 3-aminopropylmethyldiethoxysilane and N-(2-Aminoethyl)-3aminopropylmethyldimethoxysilane on polyurethane ester foam. Polymer Degradation and Stability 2012;97(11):2340-2346.

[16] Dupont, A.L., Lavédrine, B., Cheradame, H.. Mass deacidification and reinforcement of papers and books VI. Study of aminopropylmethyldiethoxysilane treated papers. Polymer Degradation and Stability 2010;95(12):2300-2308.

[17] Souguir, Z., Dupont, A.L., Fatyeyeva, K., Mortha, G., Cheradame, H., Ipert, S., et al. Strengthening of degraded cellulosic material using a diamine alkylalkoxysilane. RSC Advances 2012;2:7470-7478.

[18] Ipert, S., Dupont, A.L., Lavédrine, B., Bégin, P., Rousset, E., Cheradame, H.. Mass deacidification of papers and books IV. A study of papers treated with aminoalkylalkoxysilanes and their resistance to aging. Polymer Degradation and Stability 2006;91(12):3448-3455.

[19] ASTM, . Standard D2244-02, standard test method for calculation of color differences from instrumentally measured color coordinates. 2003.

[20] Binnie, N.. Canadian conservation institute. 2011. Personal communication. 
[21] ASTM, . Standard D3574-03, standard test methods for flexible cellular materials - slab, bonded and molded urethane foams. 2003.

[22] Massiot, D., Fayon, F., Capron, M., King, I., Le Calvé, S., Alonso, B., et al. Modelling one- and two-dimensional solid-state NMR spectra. Magnetic Resonance in Chemistry 2002;40(1):70-76.

[23] Pellizzi, E., Lattuati-Derieux, A., Lavédrine, B., Cheradame, H.. Flexible polyurethane ester foam consolidation: Preliminary study of aminopropylmethyldiethoxysilane reinforcement treatment. In: Symposium 2011 Adhesives and Consolidants for Conservation. Canadian Conservation Institute; 2011,Http://www.cci-icc.gc.ca/symposium/2011/indexeng.aspx.

[24] Bennevault-Celton, V., Maciejak, O., Desmazires, B., Cheradame, H.. Condensation of alkoxysilanes in alcoholic media: I. Oligomerization of dimethyldiethoxysilane. Polymer International 2010;59(1):43-54.

[25] Souguir, Z., Dupont, A.L., d'Espinose de Lacaillerie, J.B., Lavédrine, B., Cheradame, H.. Chemical and physicochemical investigation of an aminoalkylalkoxysilane as strengthening agent for cellulosic materials. Biomacromolecules 2011;12(6):2082-2091.

[26] Royan, L., Pellizzi, E.. Application of aminoalkylalkoxysilane consolidant on polyurethane ester foam from a Ben Vautier's work of art. 2013. Future Talks Conference, Munich, 22-25 October 2013. 